\title{
Prediction of Meteorological Drought in the Lower Nu River by Statistical Model
}

\author{
Wenhua Chen ${ }^{1}$, Juan $\mathrm{Xu}^{1 *}$, Shuangcheng $\mathrm{Li}^{2}$ \\ ${ }^{1}$ School of Resources and Environment, Baoshan University, Baoshan, China \\ ${ }^{2}$ College of Urban and Environmental Sciences, Peking University, Beijing, China \\ Email: ^xjuane@163.com
}

How to cite this paper: Chen, W. H., $\mathrm{Xu}$, J., \& Li, S. C. (2020). Prediction of Meteorological Drought in the Lower $\mathrm{Nu}$ River by Statistical Model. American Journal of Climate Change, 9, 87-99.

https://doi.org/10.4236/ajcc.2020.92007

Received: December 31, 2019

Accepted: May 9, 2020

Published: May 12, 2020

Copyright () 2020 by author(s) and Scientific Research Publishing Inc. This work is licensed under the Creative Commons Attribution International License (CC BY 4.0).

http://creativecommons.org/licenses/by/4.0/

(c) (i) Open Access

\begin{abstract}
Global climate change, temperature rise and some kinds of extreme meteorological disaster, such as the drought, threaten the development of the natural ecosystem and human society. Forecasting in drought is an important step toward developing a disaster mitigation system. In this study, we utilized the statistical, autoregressive integrated moving average (ARIMA) model to predict drought conditions based on the standardized precipitation index (SPI) and standardized precipitation evapotranspiration index (SPEI) in a major tributary in the lower reaches of $\mathrm{Nu}$ River. We employed data from 2001 to 2010 to fit the model and data from 2011 to 2013 for model validation. The results showed that the coefficients of determination $\left(\mathrm{R}^{2}\right)$ was over 0.85 in each index series, and the root-mean-square error and mean absolute error were low, implying that the ARIMA model is effective and adequate for this region.
\end{abstract}

\section{Keywords}

Meteorological Drought, Climate Change, Lower Nu River, Statistical Model

\section{Introduction}

Global climate change, rising temperatures, and various extreme meteorological conditions have seriously threatened the natural ecosystem and the development of human society and economy (Vicente-Serrano et al., 2012). In different time and space scales, the impact of drought on humans is more extensive and far-reaching than any other natural disaster. In the past two decades, drought-affected regions and areas have increased in all continents worldwide (Dai, 2010).

Drought is a natural phenomenon, which reflects the climate change and 
moisture in a region for a long time. Insufficient long-term precipitation in meteorological factors is usually the main reason for the formation of drought. Determining when droughts occur and end is often difficult because the effects of droughts can sometimes last for months ( $\mathrm{Li}$ et al., 2015), and sometimes for years. Another challenge and the fundamental aspect of drought research are determining its occurrence and severity. To quantify the extent of drought, various drought indices have been developed. For example, research on meteorological drought includes relative humidity index, percentage of precipitation anomaly, standardized precipitation index (SPI), and Palmer index (PDSI), etc. (Dai, 2013; Li \& Zhou, 2014). Among them, there are some algorithms for improving and perfecting these drought indexes. Vicente-Serrano et al. (2010) proposed a standardized precipitation evapotranspiration index (SPEI) based on the SPI index and added consideration of evaporation effects. In addition, the indexes that use river runoff as indicators to describe drought include runoff drought index (SDI), standard runoff index (SRI), standard hydrological index (SHI), etc. (Sharma \& Panu, 2014). Tsakiris et al. (2013) proposed a method that can systematically assess the interactions between meteorology, runoff drought, and economic and environmental impacts on a river basin scale.

In the past ten years, with the increasing trend of drought on a global scale, southwest China and surrounding countries have also been affected ( $\mathrm{He}$ et al., 2011). In particular, since the fall of 2009 , the effects of successive droughts have led to large-scale reductions in crop yields and even crop failure. Many reservoirs and small lakes are on the brink of dryness. Living difficulties of mountainous people and agricultural water are further exacerbated, and the ecological environment is greatly affected. It is located in the lower reaches of the $\mathrm{Nu}$ River basin in the mountains of southwestern China, and it is not only an important food production base in western Yunnan province, but also a large part of it is a hotspot for international ecological protection. The terrain in this area is dominated by river valleys and mountains distributed north-south direction. Due to the "channel" of the longitudinal valleys and the "barrier" of the mountains, the climate and environment change are complex, and it is an ecologically sensitive and fragile area in the plateau and mountains (Becker \& Bugmann, 2001). At present, the research on Lancang-Mekong River, Red River and other river basins near the $\mathrm{Nu}$ River shows that under the interactive influence of climate change and human activities, the hydrological process of the basin has changed, causing a series of ecological and hydrological problems, which have attracted widespread attention from the international community (Giang et al., 2013; $\mathrm{He}$ et al., 2014). At present, there are some studies on the characteristics of changes in precipitation, runoff and other factors in the Nu River basin (Fan \& He, 2012; Liu \& He, 2013), but few study done on the drought (Xu, 2017), A few related studies show that the meteorological drought in the lower reach of the Nu River showed an increasing trend from 1966 to 2013, but it reflects multi-scale periodic characteristics (Chen el al., 2019). In particular, the meteorological drought at 
the half-year and seasonal levels has increased significantly since the early $21^{\text {st }}$ century.

In view of the limited long-term monitoring data (precipitation, temperature, etc.) on drought in the $\mathrm{Nu}$ River Basin, this paper will use ARIMA, seasonal ARIMA and other time series model methods to explore the SPI and SPEI indicators of meteorological drought in the lower reaches of the Nu River in Yunnan Province. Try to predict future drought conditions. Provide scientific support for regional drought monitoring, industrial restructuring, and researches on the transboundary water resources changes in international basin.

\section{Study Area and Data}

\subsection{Study Area}

The study area, the Minbo River Basin, is located in Yunnan Province, China, and is a primary tributary to the lower reaches of the Nu River (Figure 1). The basin area is $6646.4 \mathrm{~km}^{2}$, the river length is $193 \mathrm{~km}$, and the total drop is $2280 \mathrm{~m}$ (ECERLC, 2014). The basin as a whole is a subtropical humid climate with four distinct seasons. The average annual temperature of Baoshan in the upper reaches of the basin is $15.6^{\circ} \mathrm{C}$, and the average annual temperature of the Jiuchang station in the lower reaches is $21.2^{\circ} \mathrm{C}$. The average annual rainfall is $1160 \mathrm{~mm}$, and the flood season is from May to November each year, and its precipitation accounts for $85 \%$ of the annual precipitation. There are many small plains distributed between the mountains in the basin, which is an important food production base in Yunnan Province. Economic crops such as coffee, tea,
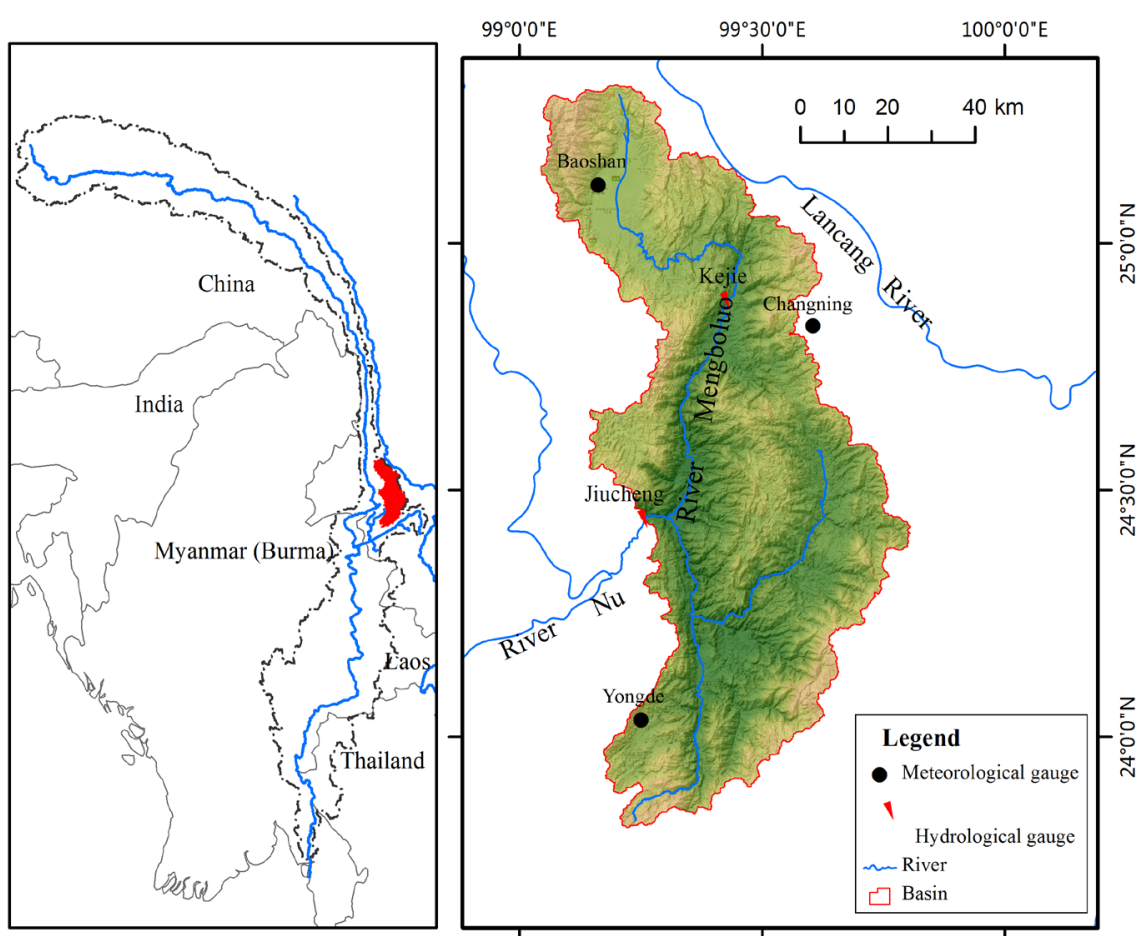

Figure 1. Location of the study area. 
and walnut are also grown on the mountains (Li \& Liu, 2004; Jiang, 2006). The development of these industries all depends on the basin's meteorological and hydrological conditions. According to the "Yunnan Disaster Reduction Yearbook", in recent years, there have been major droughts in Baoshan in 2005 and continuous droughts from 2009 to 2012. In particular, since autumn 2009 to 2012, due to the control of westerly airflow, the rainfall in the whole region was significantly less during the rainy season, and the range affected by drought was wider and the severity was higher. Among them, the Longyang District of Baoshan City in the upper reaches of the Nu River Basin had a rainfall of $100 \mathrm{~mm}$ in 2012, which was $91 \mathrm{~mm}$ less than the same period of previous years. Due to the uneven distribution of rainfall areas and rainfall periods, and the cumulative effect of the effects of less precipitation for three years, the drought situation is more severe, reaching the severe drought level.

\subsection{Data}

Three national meteorological stations (Figure 1) involved in the study area were obtained from the Yunnan Meteorological Bureau: Baoshan Station, Changning Station, Yongde Station, monthly precipitation and monthly average temperature data from 1966 to 2013. Hydrological data were obtained by the Hydrological and Water Resources Bureau of Yunnan Province from 1966 to 2013 for the monthly runoff of Kejie station and the Jiucheng station on the lower reaches of the Luobo River. According to the data of the global bioclimatic zone divided by (Metzger et al., 2012), Baoshan, Changning, and Yongde stations are located in three types of bioclimatic zones: warm and dry area, dry and hot area, and Warm and humid area. The correlation and consistency of precipitation and temperature between the three meteorological stations are high (Chen el al., 2019), so the average of the precipitation and temperature series of the three stations represents the overall situation of the river basin.

\section{Methods}

\subsection{SPI and SPEI}

The SPI is one of the main indicators recommended by the World Meteorological Organization for describing drought events. The index can be calculated using only accumulated precipitation data for different reference periods. Because the indicators are standardized, they can be compared in different regions. It first calculates the $\Gamma$ distribution probability of precipitation in a specific reference period, and then normalizes the cumulative frequency of precipitation through the Log-normal function (WMO, 2012). The calculation of the SPEI is similar to that of the SPI, the main difference is that the increase of evapotranspiration on the effect of drought (Vicente-Serrano et al., 2010). Considering the rainfall patterns in the lower reaches of the Nu River, in the short reference period, SPI and SPEI only show periodic time oscillations, and it is difficult to evaluate long-term drought changes (Patel et al., 2007; Tigkas et al., 2012; Shi el al., 
2015), in contrast, it is easier to identify drought events with calculated values for longer reference periods. Therefore, we chose a 12-month reference period to analysis the annual level of drought characteristics in the study area. The levels of drought indicators are classified as follows (Table 1), according to the SPI level in "Meteorological drought level" (GB/T20481-2006) and related research (Soumyashri \& Nagraj, 2016).

\subsection{ARIMA and Seasonal ARIMA}

The commonly used forecast tools for the time series is a data-driven methods, namely Autoregressive Integrated Moving Average (ARIMA) model (Hao et al., 2018). For a certain time series (such as drought indicator series), ARIMA emphasizing the stochastic properties of the series rather than its constructing single. Each variable in the model is represented by the lag of the series and the stochastic error. The common ARIMA model consists of a p-order AR (autoregressive) model, a $q$-order MA (moving average) model, and a $d$-order difference operator on the time series (Box et al., 2015). This can be expressed as $\operatorname{ARIMA}(p, d, q)$.

Box et al. extended the common ARIMA model to deal with the periodicity in the time series, with the result form a new ARIMA model, namely Seasonal ARIMA (Box et al., 2015). The SARIMA model is constructed by adding seasonal periodic rule to a general ARIMA mode, and it could be denoted as ARIMA $(p, d, q)(s p, s d, s q)_{s}$ where $(p, d, q)$ is the nonseasonal component of the model, and $(s p, s d, s q)_{s}$ is the seasonal component. where $p$ is the order of AR model, $q$ is the order of the MA model, $d$ is the order of the difference, Correspondingly, $s p$ is the order of the seasonal AR, $s q$ is the order of the seasonal MA, $s d$ is the order of seasonal difference, and $s$ is the seasonal span.

ARIMA model has low requirements for input data, few model parameters, and fast optimization speed. It is well adapt to non-stationary data (Alam et al., 2014). Based on these advantages, this model is more suitable for hydrological prediction in the area with lacking data. However, because the parameters of the model are based on the change rule of historical data, when the climate of the study area changes significantly, the prediction accuracy will decrease, also the prediction period should not be set too long (Yeh \& Hsu, 2019).

\subsection{Model Development}

The time series modeling method is used to fit the SPI and SPEI sequences. The basic process includes: model identification, parameter estimation and model diagnosis. The indicator series (SPI-12M, SPEI-12M) from 2001 to 2010 were

Table 1. Drought index ranks of SPI and SPEI.

\begin{tabular}{|c|c|c|c|c|c|}
\hline Index & Non-dro & Mild-drought & Moderate drought & Severe drought & Extreme drought \\
\hline SPI & & $-1.0<\mathrm{SPI} \leq-0.5$ & $-1.5<\mathrm{SPI} \leq-1.0$ & & \\
\hline SPEI & $-0.5<$ SPEI & $-1.0<\mathrm{SPEI} \leq-0.5$ & $-1.5<\mathrm{SPEI} \leq-1.0$ & $-2.0<\mathrm{SPEI} \leq-1.5$ & SPEI $\leq-2.0$ \\
\hline
\end{tabular}


simulated and used for verification from 2011 to 2013.

\subsubsection{Model Recognition and Parameter Estimation}

The construction of ARIMA/SARIMA model requires the time series to be a stationary process. Therefore, the first step in model identification is to perform a stationary test on the original time series. Take the 2001-2013 time series and use the ADF test method to check the sequence stability. If the sequence is unstable, perform differential processing and repeat the test process until the sequence is stable (Table 2).

In the model recognition stage, ARIMA/SARIMA models were selected as candidate models, and the grid search method was used for parameter optimization. In the optimization process, AIC (Akaike information criterion) and SBC (Schwarz-Bayes information criterion) are used for judgment: models with lower AIC and SBC values are considered to have better fitting effects. Calculations for AIC and SBC may refer to related literature (Akaike, 1974; Schwarz, 1978). Finally, after identifying the model, the parameters of the model need to be estimated. In this study, the recommended maximum likelihood method (Box et al., 2015), which is often used for statistical model parameter estimation, is used to estimate model parameters.

\subsubsection{Diagnostic Checking}

After the parameter estimation is completed, a diagnostic check is performed. The statistical check of the residuals is mainly performed to verify whether the model is suitable for time series. For a well-performing model, the residuals must satisfy independence, obey normal distribution, and homogeneity of variance. That is, the residual must be a white noise process. Some statistical tests and residual plots are used for diagnostic tests. The residual autocorrelation function (RACF) and residual partial autocorrelation function (RPACF) of the time series can be used to determine whether the series is independent. If the ACF and PACF of the residuals are significant within the confidence interval, it indicates that there is no significant correlation between the residuals.

Another method is to use Ljung-Box-Pierce (LBQ) to test. If the Q statistic is less than ( $\alpha=0.05$ level) critical value, the residual error is white noise. This paper uses Ljung-Box-Pierce (LBQ) to test the independence of residuals. Normality of residuals is verified by histograms and residual probability plots; the homogeneity of residuals is verified by scatter plots of residuals and predicted values. If there is no obvious pattern in the scatter plot and the residuals are randomly distributed around 0 . It indicates that the residuals are homogeneous.

Table 2. P value of ADF test for drought index series.

\begin{tabular}{ccccc}
\hline Index & Scale & Original series & Difference Order & Difference series \\
\hline SPI & M12 & 0.1093 & 1 & ${ }^{*} 0.0000$ \\
SPEI & M12 & 0.0642 & 1 & ${ }^{\star} 0.0000$
\end{tabular}

Note: ${ }^{\star}$ represents a significant level of 0.05 . 


\section{Results and Discussion}

\subsection{Drought Change Characteristics}

According to previous studies, the SPI and SPEI time series have dropped significantly after 2000 (Chen el al., 2019). Here, we take the year 2000 as the breakpoint, and counted the frequency of occurrence of moderate or higher droughts (value $<-1$ ) in each month, which are represented by SPI and SPEI indicators, in the study area from 1966 to 2000 and from 2001 to 2013. There are some differences in the frequency of drought reflected by different indicators. In general, the drought frequency of SPEI is higher than that of SPI. Since the beginning of the 21st century, the frequency of droughts reflected by the two indicators has increased significantly from 1966 to 2000 (Figure 2). During the period from 1966 to 2000, the average frequency of moderate and higher droughts characterized by SPI and SPEI was $8.6 \%$ and $10.9 \%$. However, after 2000, the average frequency of moderate and above droughts represented by SPI and SPEI was $24.8 \%$ and $32.4 \%$, especially in the dry season months such as January-April and November-December. The frequency of moderate and above droughts even reached $29.1 \%$ (SPI) and 39.2\% (SPEI).

\subsection{Model Recognition}

Figure 3 shows that the ACF curves of the SPI and SPEI index training samples are gradually attenuated in the form of a sine wave, indicating that the sequence contains periodic information. It is more appropriate to consider fitting with the SARIMA model. According to the AIC and BIC quasi-sides, the grid search method is used to set the search range to 0 - 4 . The SARIMA $(p, 1, q)(s p, 1, s q)_{12}$ model parameters are automatically optimized to obtain the minimum AIC The best model for BIC is shown in Table 3. The one with the fewest parameters is selected as the best model. The analysis of model coefficients, related standard errors, and standard error probabilities is shown in Table 4. It can be seen from the table that the selected SARIMA model performs well in both series.

\subsection{Diagnostic Checking}

The Ljung-Box-Pierce statistic was used to test the independence of the residuals.
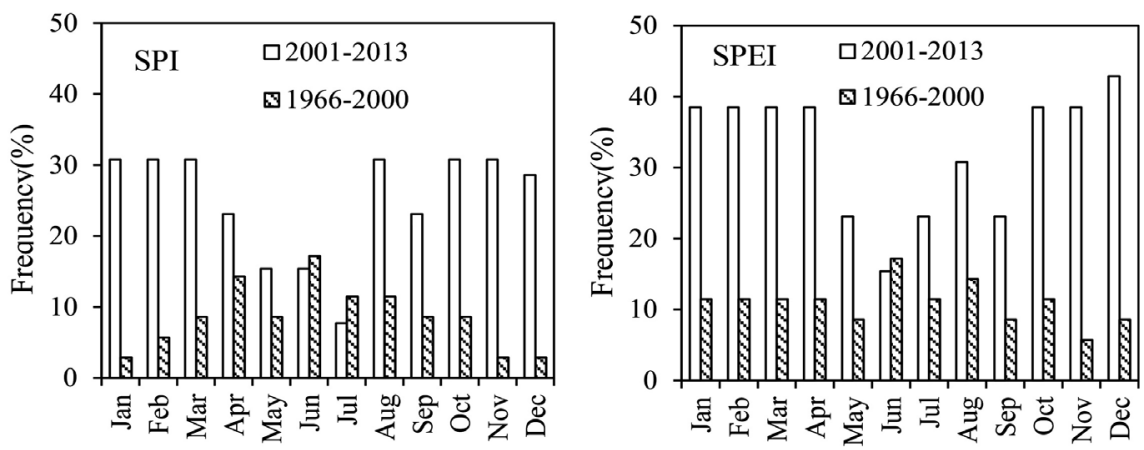

Figure 2. Frequency \% of occurrence in moderate and severe drought from SPI (left) and SPEI (right). 

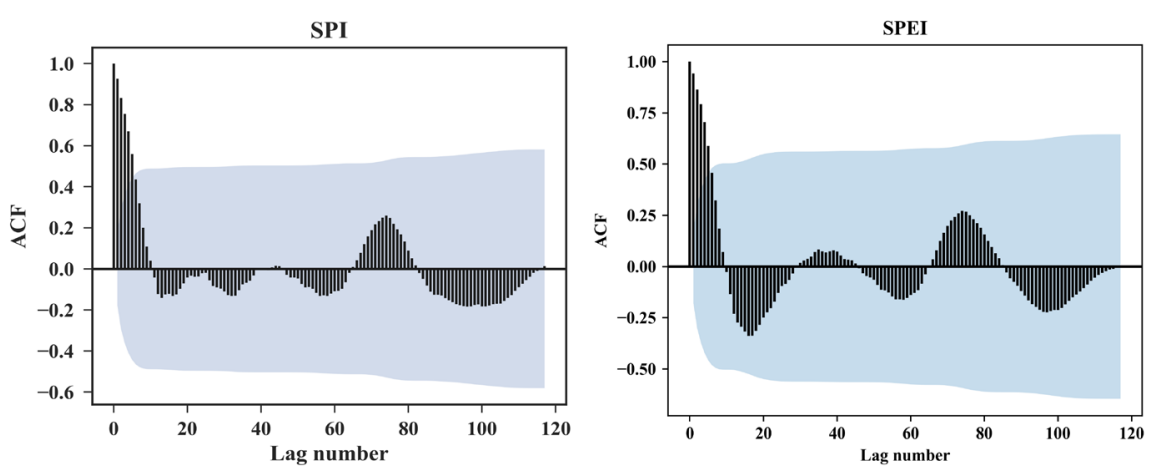

Figure 3. ACF of drought series for SPI (left) and SPEI (right).

Table 3. AIC and SBC score for candidate ARIMA model.

\begin{tabular}{cccc}
\hline Series & Model & AIC & SBC \\
\hline \multirow{2}{*}{ SPI } & SARIMA $(2,1,2) \times(1,0,2) 12$ & 26.229 & 46.403 \\
& $\operatorname{SARIMA}(0,1,0) \times(2,0,0) 12$ & 38.248 & 45.91 \\
\multirow{2}{*}{ SPEI } & $\operatorname{SARIMA}(1,1,1) \times(2,0,1) 12$ & 14.554 & 29.814 \\
& $\operatorname{SARIMA}(0,1,0) \times(2,0,1) 12$ & 15.946 & 26.162 \\
\hline
\end{tabular}

Table 4. Statistical analysis of model parameters.

\begin{tabular}{cccccc}
\hline Series & Item & Coefficient & Std error & $\mathrm{z}$ & $\mathrm{P}>|\mathrm{z}|$ \\
\hline \multirow{3}{*}{ SPI } & ar.S.L12 & -0.7231 & 0.0820 & -8.7680 & 0.0000 \\
& ar.S.L24 & -0.2554 & 0.1200 & -2.1240 & 0.0340 \\
& $\sigma^{2}$ & 0.0822 & 0.0090 & 9.2060 & 0.0000 \\
& ar.S.L12 & -0.3693 & 0.1250 & -2.9590 & 0.0030 \\
\multirow{3}{*}{ SPEI } & ar.S.L24 & -0.1478 & 0.1160 & -1.2730 & 0.2030 \\
& ma.S.L12 & -0.5980 & 0.1370 & -4.3550 & 0.0000 \\
& $\sigma^{2}$ & 0.0602 & 0.0080 & 7.9850 & 0.0000 \\
\hline
\end{tabular}

The $\mathrm{Q}$ value is compared with the critical value of a significant level of $\alpha=0.05$ under the corresponding degrees of freedom. In all cases, the test results are not significant, indicating that the model's residuals are white noise (Table 5).

Figure 4 and Figure 5 depict the histograms (Histogram plus estimated density of standardized residuals, along with a normal $(0,1)$ density) and normal QQ plots of the SPI and SPEI simulation residuals, respectively. The histogram shows that the residuals are roughly concentrated around zero and are approximately normally distributed. The normal QQ plot of the residuals shows that the residuals are basically located on a diagonal, and also indicates the normal distribution of the residuals.

The residual homogeneity is tested by the residual scatter plot and predicted values. The results are shown in Figure 6. There are no specific patterns of scatter, and the residuals are randomly distributed. That is, the residuals are evenly distributed around the zero mean, which means that the model fits well. 
Table 5. Ljung-Box-Pierce statistics for the residuals.

\begin{tabular}{ccc}
\hline Series & Ljung-Box $(\mathrm{Q})$ & Critical value \\
\hline SPI & 26.3 & 145.461 \\
SPEI & 42.9 & 145.461 \\
\hline
\end{tabular}
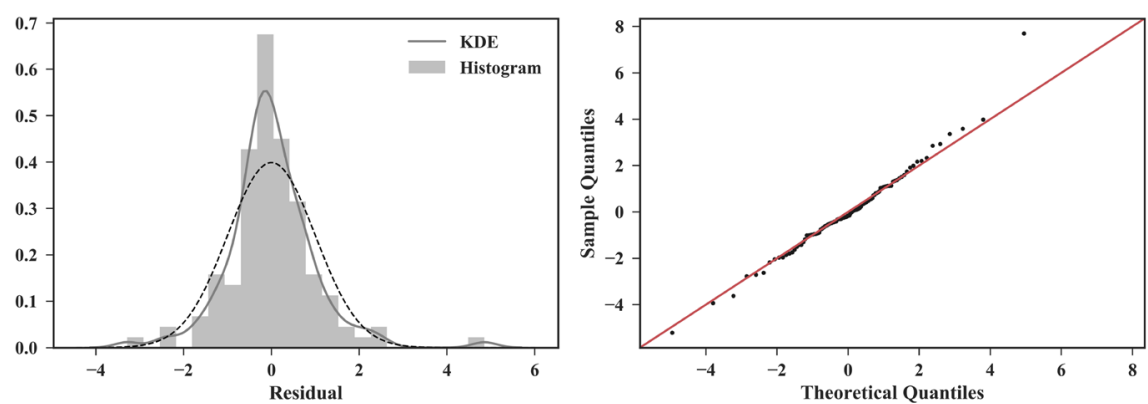

Figure 4. Histogram (left) and Normal QQ plot (right) of residuals for SPI.
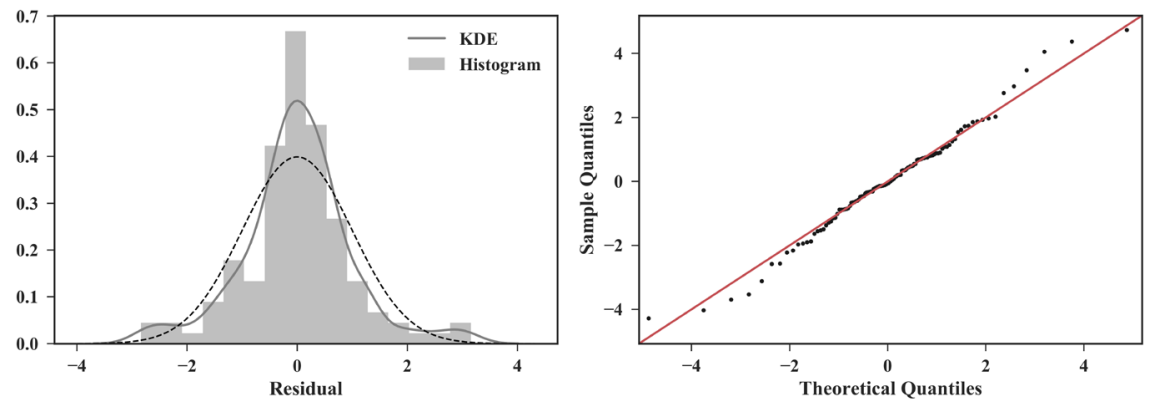

Figure 5. Histogram (left) and Normal QQ plot (right) of residuals for SPEI.
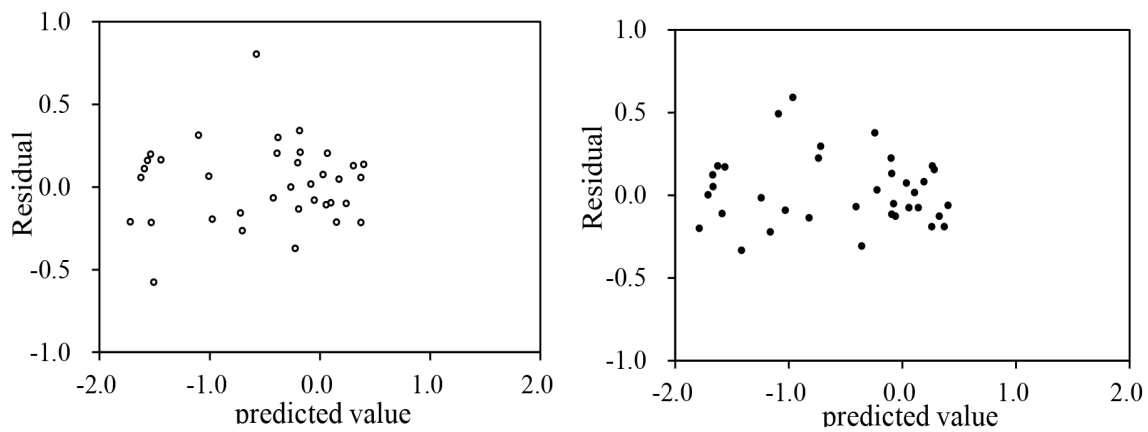

Figure 6. Scatter plot of the residual against predicted value for SPI (left) and SPEI (right).

Here, we also compare the observations with the optimal simulation values of the series from 2008 to 2010 (intra-sample data). Figure 7 shows the comparison between the predictions and observations of SPI and SPEI series. It can be seen that the prediction and the observation series have similar characteristics and also, the $95 \%$ prediction uncertainties $(95 \mathrm{ppu})$ shows a relatively narrower band. The performance indicators for the model are shown in Table 6. In general, the higher $\mathrm{R}^{2}$, the better the performance of the model. The results show that 

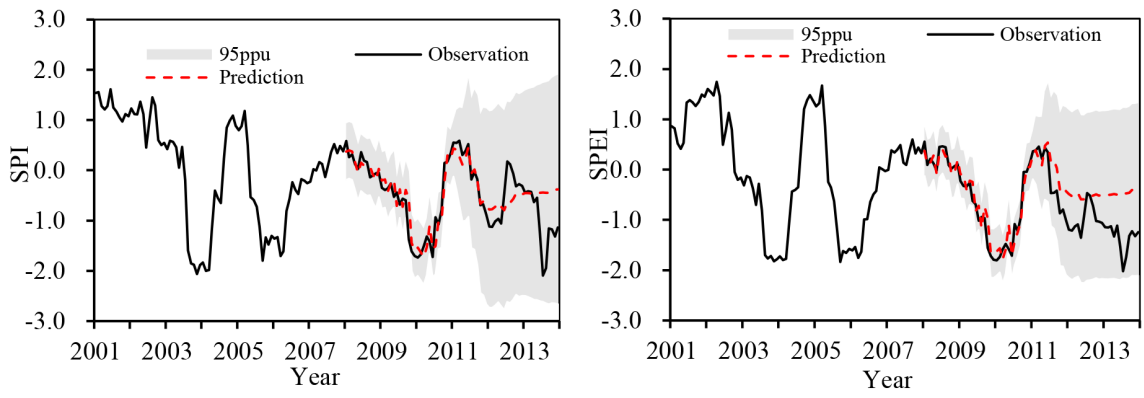

Figure 7. Comparison of predicted SPI (left), SPEI (right) to their observed value between 2008 and 2013.

Table 6. Performance measures about SARIMA for the observed data and predicted value.

\begin{tabular}{ccccc}
\hline Series & Model & $\mathrm{R}^{2}$ & RMSE & MAE \\
\hline SPI & SARIMA $(0,1,0) \times(2,0,0) 12$ & 0.89 & 0.242 & 0.187 \\
SPEI & SARIMA $(0,1,0) \times(2,0,1) 12$ & 0.93 & 0.208 & 0.164 \\
\hline
\end{tabular}

the $\mathrm{R}^{2}$ of both models are greater than 0.85 , and the root mean square error (RMSE) and average absolute error (MAE) are relatively lower.

\subsection{Model Validation}

The calculation was performed using the best-fit SARIMA model. The SPI and SPEI sequence values from 2011 to 2013 (out-of-sample data) were simulated. See Figure 6 and Figure 7 for the comparison between observed and predicted series. After test the correlations between observation and prediction value, and checked the root mean square error (RMSE) for time span of 12, 24, and 36 months in advance, it was found that with the extension of the prediction period, the accuracy and uncertainty of the model decrease (Table 7) and increase (Figure 7) significantly respectively.

Although the value of the hydrological drought index estimated using the SARIMA model is still uncertain, the intensity of the hydrological drought is mainly expressed by the index level rather than the absolute value of the index. Therefore, the model is useful in the prediction of short-term change and long-term trend of drought. Using these SPI or SPEI-based drought indices and the established SARIMA model for drought forecasting has certain application value for mitigating drought in the study area.

\section{Conclusion}

This paper compares the occurrence frequency of moderate and above-average droughts (values $<-1$ ) in each month as represented by the SPI and SPEI indicators in the lower reaches of the Nu River. It is found that since the beginning of the 21 st century, the frequency of droughts reflected by the two indicators has increased significantly from 1966 to 2000 , and the SPEI drought frequency is 
Table 7. Performance measures about SARIMA for the out sample data prediction.

\begin{tabular}{ccccc}
\hline \multirow{2}{*}{ Months } & \multicolumn{2}{c}{ SPI } & \multicolumn{2}{c}{ SPEI } \\
\cline { 2 - 5 } & $\mathrm{R}^{2}$ & RMSE & $\mathrm{R}^{2}$ & RMSE \\
\hline 12 & 0.928 & 0.154 & 0.773 & 0.397 \\
24 & 0.082 & 0.528 & 0.012 & 0.530 \\
36 & 0.001 & 0.591 & 0.000 & 0.929 \\
\hline
\end{tabular}

higher than the SPI drought frequency. This provides further evidence for the fact that the increase in meteorological drought in the region was dominated by previous studies (Chen el al., 2019). Based on this, this paper uses the time series stochastic model (ARIMA) to simulate the drought process in this area, and can draw the following conclusions:

1) The temporal characteristics of meteorological drought in the lower reaches of the $\mathrm{Nu}$ River indicate that the region may experience drought in almost all months of the year (i.e., SPI $<0$ ).

2) The stochastic model developed to predict drought has achieved good simulation results in predicting medium and short-term drought (within 12 months).

3) The linear stochastic model can be used to quickly predict watershed droughts with scarce data, analyze the severity of future droughts, and also be used by local governments and resource planners to predict drought severity in advance.

The stochastic model predicts the SPI and SPEI time series, which provide a convenient tool for forecasting meteorological drought in the lower reaches of the $\mathrm{Nu}$ River. However, due to many factors, changes in natural phenomena related to drought are complex. Stochastic models do not consider physical processes, so it is difficult to understand climate change from the physical mechanism behind it. In addition, the model assumptions may lead to higher uncertainty when we extend the prediction period. However, the model can be used to predict the short-term change and the future trends of the drought, and it may also be used as a reference for further research on other prediction models.

\section{Funding}

Science Research Fund Project of Yunnan Provincial Department of Education, China: Study on Water Security Patterns in Mountainous Cities: A Case Study of Baoshan City (2019J0338).

\section{Conflicts of Interest}

The authors declare no conflicts of interest regarding the publication of this paper.

\section{References}

Akaike, H. (1974). A New Look at the Statistical Model Identification. IEEE Transactions on Automatic Control, 19, 716-723. https://doi.org/10.1109/TAC.1974.1100705 
Alam, N. M., Mishra, P. K., Jana, C., \& Adhikary, P. P. (2014). Stochastic Model for Drought Forecasting for Bundelkhand Region in Central India. Indian Journal of Agricultural Sciences, 84, 79-84.

Becker, A., \& Bugmann, H. (2001). Global Change and Mountain Regions: The Mountain Research Initiative. IGBP Report, IGBP Secretariat, No. 49. Stockholm, Sweden.

Box, G. E. P., Jenkins, G. M., Reinsel, G. C., \& Ljung, G. M. (2015). Time Series Analysis: Forecasting and Control (pp. 712). Hoboken, NJ: John Wiley \& Sons, Inc.

Chen, W. H., Xu, J., \& Li, S. C. (2019). A Study on the Characteristics of Hydrological and Meteorological Droughts in the Lower Nu River. Acta Scientiarum Naturalium Universitatis Pekinensis, 55, 764-772. (In Chinese)

Dai, A. G. (2010). Drought under Global Warming: A Review. Climate Change, 2, 45-65. https://doi.org/10.1002/wcc.81

Dai, A. G. (2013). Increasing Drought under Global Warming in Observations and Models. Nature Climate Change, 3, 52-58. https://doi.org/10.1038/nclimate1633

ECERLC (2014). Encyclopedia of Rivers and Lakes in China: Section of River Basins in Southwest Region. Beijing: China Water Power Press.

Fan, H., \& He, D. M. (2012). Regional Climate and Its Change in the Nujiang River Basin. Acta Geographica Sinica, 67, 621-630. (In Chinese)

Giang, P. Q., Toshiki, K., Kunikane, S., \& Sakata, M. (2013). Climate Change Challenges Transboundary Water Resources Management: Drawing from the Case of Vietnam. Kuala Lumpur.

Hao, Z., Singh, V. P., \& Xia, Y. (2018). Seasonal Drought Prediction: Advances, Challenges, and Future Prospects. Reviews of Geophysics, 56, 108-141. https://doi.org/10.1002/2016RG000549

He, D. M., Wu, R. D., Feng, Y., Li, Y. G., Ding, C. Z., Wang, W. L., \& Yu, D. W. (2014). China's Transboundary Waters: New Paradigms for Water and Ecological Security through Applied Ecology. Journal of Applied Ecology, 51, 1159-1168. https://doi.org/10.1111/1365-2664.12298

He, J., Zhang, M., Wang, P., Wang, S., \& Wang, X. (2011). Climate Characteristics of the Extreme Drought Events in Southwest China during Recent 50 Years. Acta Geographica Sinica, 66, 1179-1190. (In Chinese)

Jiang, G. (2006). Baoshan Yearbook. Kunming: Yunnan Ethnic Publishing House. (In Chinese)

Li, B., \& Zhou, G. (2014). Advance in the Study on Drought Index. Acta Ecologica Sinica, 34, 1043-1052. (In Chinese) https://doi.org/10.3724/SP.J.1041.2014.01043

Li, M., \& Liu, S. (2004). Chronicles of Lincang District. Beijing: Beijing Yanshan Press. (In Chinese)

Li, P., Feng, Y., \& Zhao, X. (2015). Spatiotemporal Variability in Water Cycle of Cropland in the North Part of Northern China Plain from 2002 to 2011. Acta Scientiarum Naturalium Universitatis Pekinensis, 51, 1111-1118. (In Chinese)

Liu, X. Y., \& He, D. M. (2013). Temporal and Spatial Distribution and Its Change Trend of Suspended Sediment Transport in the Nujiang River Basin. Acta Geographica Sinica, 68, 365-371. (In Chinese)

Metzger, M. J., Bunce, R. G. H., Jongman, R. H. G., Sayre, R., Trabucco, A., \& Zomer, R. (2012). A High-Resolution Bioclimate Map of the World: A Unifying Framework for Global Biodiversity Research and Monitoring. Global Ecology and Biogeography, 22, 630-638. https://doi.org/10.1111/geb.12022 
Patel, N. R., Choprab, P., \& Dadhwal, V. K. (2007). Analyzing Spatial Patterns of Meteorological Drought Using Standardized Precipitation Index. Meteorological Applications, 14, 329-336. https://doi.org/10.1002/met.33

Schwarz, G. (1978). Estimating the Dimension of a Model. The Annals of Statistics, 6, 461-464. https://doi.org/10.1214/aos/1176344136

Sharma, T. C., \& Panu, U. S. (2014). Modeling of Hydrological Drought Durations and Magnitudes: Experiences on Canadian Streamflows. Journal of Hydrology Regional Studies, 1, 92-106. https://doi.org/10.1016/j.ejrh.2014.06.006

Shi, B., Zhu, X., Hu, Y., \& Yang, Y. (2015). Spatial and Temporal Variations of Drought in Henan Province over a 53-Year Period Based on Standardized Precipitation Evapotranspiration Index. Geographical Research, 34, 1547-1558. (In Chinese)

Soumyashri, R., \& Nagraj, S. P. (2016). Drought Analysis Based on Streamflow Drought Index (SDI) in Bhima Sub-Basin. International Journal of Advanced Engineering Research and Applications, 2, 154-159.

Tigkas, D., Vangelis, H., \& Tsakiris, G. (2012). Drought and Climatic Change Impact on Streamflow in Small Watersheds. Science of the Total Environment, 440, 33-41. https://doi.org/10.1016/j.scitotenv.2012.08.035

Tsakiris, G., Nalbantis, I., Vangelis, H., Verbeiren, B., Huysmans, M., Tychon, B., Jacquemin, I., Canters, F., Vanderhaegen, S., Engelen, G., Poelmans, L., De Becker, P., \& Batelaan, O. (2013). A System-based Paradigm of Drought Analysis for Operational Management. Water Resources Management, 27, 5281-5297.

https://doi.org/10.1007/s11269-013-0471-4

Vicente-Serrano, S. M., Beguería, S., \& López-Moreno, J. I. (2010). A Multiscalar Drought Index Sensitive to Global Warming: The Standardized Precipitation Evapotranspiration Index. Journal of Climate, 23, 1696-1718. https://doi.org/10.1175/2009JCLI2909.1

Vicente-Serrano, S. M., Gouveia, C., Camarero, J. J., Beguería, S., Trigo, R., López-Moreno, J. I., Azorín-Molina, C., Pasho, E., Lorenzo-Lacruz, J., Revuelto, J., Morán-Tejeda, E., \& Sanchez-Lorenzo, A. (2012). Response of Vegetation to Drought Time-Scales across Global Land Biomes. Proceedings of the National Academy of Sciences, 110, 52-57. https://doi.org/10.1073/pnas.1207068110

WMO (2012). Standardized Precipitation Index User Guide. World Meteorological Organization.

$\mathrm{Xu}$, J. (2017). A Study of Meto-Drought in Nujiang and Lancang River Basins in Yunnan Province during Recent 50 Years. Acta Scientiarum Naturalium Universitatis Pekinensis, 53, 964-972. (In Chinese)

Yeh, H. F., \& Hsu, H. (2019). Stochastic Model for Drought Forecasting in the Southern Taiwan Basin. Water, 11, 2041. https://doi.org/10.3390/w11102041 